\title{
Variação Linguística na Escola: Propostas de Acãa
}

\author{
Linguistic Variation in School: Proposals for Action
}

\author{
Joyce Elaine Almeida BARONAS *
}

Resumo: A necessidade de estudos específicos que envolvam as diversas normas linguísticas deu luz à elaboração da presente pesquisa, que busca propiciar subsídios ao trabalho do professor de Língua Portuguesa. Trata-se de uma proposta de ação direcionada a uma mudança de perspectiva em sala de aula, buscando incutir aspectos teóricos relacionados à variação linguística no trabalho docente com o propósito de aprimorar sua prática, mais especificamente no que diz respeito ao ensino da língua portuguesa abrangendo as diversas normas linguísticas.

Palavras-chave: Variação linguística; Ensino de língua português; Norma.

Abstract: The need for specific studies involving the various linguistic norms gave birth to the preparation of this research that seeks to provide grants to teachers work in Portuguese. This is a proposal for action directed at a change of perspective in the classroom, trying to instill theoretical aspects related to language variation in teaching in order to improve their practice, specifically with regard to the teaching of Portuguese language covering the various linguistic norms.

Key-words: Linguistic variation; Teaching of Portuguese language; Linguistic norm.

* Doutorado em Linguística e Língua Portuguesa pela Universidade Estadual Paulista Júlio de Mesquita Filho (2005). Mestrado em Letras pela Universidade Estadual de Londrina (1996). Docente na Universidade Estadual de Londrina. Contato:joyal@uel.br 


\section{Introdução}

As grandes diferenças entre a língua portuguesa de Portugal e a do Brasil resultaram diversas pesquisas, havendo, atualmente, estudiosos que caracterizam a língua deste país como o português brasileiro. Em se tratando do Brasil, é possível afirmar que a língua é bastante diversificada devido a determinados motivos, como a extensa faixa territorial do país, que reúne falantes de um português diferente, ou de várias formas de um português, além dos fatores socioculturais que dinamizam a variação da língua. Com isso, a escola brasileira enfrenta questões complicadas no que diz respeito ao ensino da língua, pois os estudantes, muitas vezes, apresentam uma fala muito distante da norma padrão e, por isso, têm muita dificuldade na aquisição de tal norma. É sabido que a norma padrão é uma prescrição da modalidade escrita; a norma culta seria a mais próxima desta norma, por ser baseada na fala de pessoas com bastante familiaridade com a escrita. Entretanto, há uma grande camada da população brasileira que não tem acesso à norma culta. Tal faixa populacional é também marginalizada em situações demarcadas pela cultura escrita, pois não domina as regras desta.

O presente estudo pretende apresentar propostas de trabalho que envolvam a variação linguística na escola, objetivando fornecer subsídios aos professores de Língua Portuguesa a partir de propostas de ação que vão ao encontro do estudo da língua em suas diversificadas matizes. Nesse sentido, objetiva levar o professor a compreender os desvios da norma, presentes nos textos de seus alunos, além de propor atividades de reflexão linguística, buscando uma melhor compreensão da língua portuguesa abrangendo as variadas normas presentes no país. Espera-se, com este estudo, levar ao professor ferramentas úteis para o trabalho com a língua de forma consciente e inovadora, no sentido de romper com o preconceito linguístico e de conceber a linguagem como objeto de interação social, abordando não só a norma padrão, mas também as variedades linguísticas. 


\section{Pressupostos teóricos}

\subsection{Variação linguística}

A linguagem é, por natureza, um objeto sujeito a alterações, por ser uma parte constitutiva do ser humano. Ora, se o homem está sempre evoluindo, mudando sua aparência, suas ideias, seus valores, é perfeitamente normal haver variações e mudanças linguísticas. Segundo Labov (1962), a variação linguística é natural, é essencial à linguagem humana; desta forma, o que exigiria explicação seria a ausência da variação na linguagem e não a sua presença. Corroborando as ideias de Labov, Castilho (2010, p. 197) aponta:

As línguas são constitutivamente heterogêneas, pois através delas temos de dar conta das muitas situações sociais em que nos envolvemos, em nosso dia a dia. Elas são também inevitavelmente voltadas para a mudança, pois os grupos humanos são dinâmicos, e as línguas que eles falam precisam adaptar-se às novas situações históricas.

Pode-se, pois, afirmar que a escola deve estar preparada para o ensino de uma língua viva, heterogênea, mutável, ou seja, é necessário que o professor esteja preparado para abordar as diversas normas do país, resultantes de motivos diversos.

Coseriu (1980) afirma que a diversidade linguística pode ocorrer devido a diversos fatores e propõe uma classificação para as diferentes formas de variação: diacrônica, diatópica, diastrática e diafásica. Segundo o autor, quando há alterações linguísticas resultantes da passagem do tempo, elas se denominam diacrônicas. Como exemplo para este tipo de variação há o pronome você, enquanto resultado das mudanças na expressão Vossa Mercê.

As variações resultantes das características regionais, ou diatópicas, são representadas pelos distintos sotaques, evidenciados, por exemplo, pela diferente pronúncia do $\mathbf{r}$ em regiões paulistas e regiões nordestinas. Além dessas, as variações diatópicas também se evidenciam em outros níveis, como o lexical, por exemplo, com os variados nomes existentes para um mesmo objeto; ou o morfossintático, como a distribuição 
regional do emprego do pronome tu/você. Segundo Castilho (2010, p. 198), "de todas as variedades do português, a variedade geográfica é a mais perceptível." O autor ainda afirma que a percepção da rica variedade geográfica brasileira levou estudiosos a se dedicarem aos estudos da Dialetologia

Há, também, as alterações na linguagem resultantes dos diferentes estratos socioculturais, denominadas diastráticas, e que podem ser comprovadas com estudos comparativos entre falantes alfabetizados e analfabetos, por exemplo. Segundo Castilho (2010, p. 204):

analfabetos e cidadãos escolarizados não falam exatamente da mesma forma. Analfabetos usam o 'português popular', ou variedade não culta. Pessoas escolarizadas usam o 'português culto’, ou variedade padrão, aprendida na escola ou no ambiente familiar.

Salienta-se aqui a necessidade de lutar contra o preconceito linguístico em relação a falantes do português popular, visto que constitui uma norma tão completa e complexa como qualquer outra. Segundo Castilho (2010, p. 205):

Quem pratica o português popular não 'fala errado' - apenas opera com a variedade correspondente ao seu nível sociocultural. Quem pratica o português culto não 'fala certo', de novo apenas se serve da variedade correspondente ao seu nível sociocultural. Falar errado é não se fazer entender em seu meio, como bem lembrava o professor Antenor Nascentes, ou é usar uma variedade inadequada ao meio em que o falante se encontra.

Há também a variação diafásica, que, segundo Coseriu (1980), constitui as distinções entre os diversos tipos de modalidade expressiva. Para o autor, "as variedades lingüísticas que caracterizam - no mesmo estrato social - os grupos 'biológicos' (homens, mulheres, crianças, jovens) e os grupos profissionais podem ser consideradas como 'diafásicas'." (COSERIU, 1980, p. 110-111).

Castilho (2010) apresenta mais uma classificação entre os itens apontados por Coserio (1980), que diz respeito à variação de canal. 
Para o autor, tal classificação abrange as diferenças entre a escrita e a oralidade: "A comunicação linguística pode ocorrer em presença do interlocutor, quando falamos, ou na sua ausência, quando escrevemos. Isso nos leva à variação de canal, a língua falada e a língua escrita" (CASTILHO, 2010, p. 212).

Tais apontamentos são de relevância para o presente estudo porque defende-se aqui a interferência da fala na escrita, e, como afirma Cagliari (1999, p. 124), “a variação linguística, característica inerente a toda e qualquer língua do mundo, pode constituir um grande problema para quem está adquirindo o sistema da escrita.”. Isto porque o aluno pode transpor as variantes distantes da norma para o texto escrito. Em outro estudo, o autor ainda aponta que "o erro mais comum dos alunos é caracterizado por uma transcrição fonética da própria fala" (CAGLIARI, 1992, p. 138).

\subsection{Desvios da norma}

O texto escrito, como é sabido, exige a norma padrão; entretanto, é comum a existência de dificuldades dos alunos na assimilação desta norma, gerando incorreções de ordem gramatical e ortográfica. Mattoso Câmara, em artigo publicado em 1957, já estudava os chamados "erros escolares". Em seu estudo, o autor analisou textos de alunos de escolas particulares do Rio de Janeiro, identificando desvios da norma padrão e apontando os fenômenos ocorridos. Os textos analisados eram resultantes de ditados e de algumas questões de ordem gramatical e o autor os analisou classificando-os segundo três aspectos: fonético, morfológico e sintático. Salienta-se que, entre os 20 itens apontados pelo autor, 13 são de ordem fonética, ou seja, dizem respeito à oralidade presente no texto escrito. Finalizando seu estudo, o autor reforça a ideia da influência da oralidade na escrita ao apontar que seu objetivo, ao efetuar tal estudo, era "documentar certas tendências coletivas da língua coloquial no Brasil, ou mais especialmente no Rio de Janeiro" (MATTOSO CÂMARA, 1957, p. 95).

Miriam Lemle (1978) também aborda os desvios da norma em textos de alunos do MOBRAL - Rio. A autora efetuou seu estudo a partir da Sociolinguística Quantitativa, identificando regras variáveis que dependem de contextos linguísticos e sociais. Paiva (1984), sob 
orientação de Miriam Lemle, também analisou questões relativas à norma em sua dissertação de mestrado, em que compara textos de alunos de uma escola municipal do norte do Rio de Janeiro com textos de alunos de uma escola particular da zona sul da cidade. A pesquisadora identificou "erros" resultantes da interferência da oralidade e "erros" ortográficos, concluindo que o dialeto dos alunos da escola municipal era o fator responsável pelo maior número de "erros" comparados com os de escola particular.

Outra pesquisa direcionada a tal fenômeno é a de BortoniRicardo (2005), na qual aplica a técnica de análise e diagnose de erros, que, segundo a autora, "permite a identificação dos erros, bem como a elaboração de material didático destinado a atender às áreas cruciais de incidência" (BORTONI-RICARDO, 2005, p. 53).

A autora aponta quatro categorias de erros:

1) Erros decorrentes da própria natureza arbitrária do sistema de convenções da escrita;

2) Erros decorrentes da interferência de regras fonológicas categóricas no dialeto estudado;

3) Erros decorrentes da interferência das regras fonológicas variáveis graduais;

4) Erros decorrentes da interferência de regras fonológicas variáveis descontínuas. (BORTONI-RICARDO, 2005, p. 54)

Como se pode constatar, apenas a primeira categoria não tem relação com a oralidade, pois diz respeito à questão ortográfica. Exemplo desta ocorrência seria o fato de letras distintas representarem o mesmo fonema, como em tassa/ taça. As outras três são, como afirma a pesquisadora, "decorrentes da transposição dos hábitos da fala para a escrita” (BORTONI-RICARDO, 2005, p. 54) e se distinguem entre si.

A segunda categoria se caracteriza pela interferência de regras fonológicas categóricas, ou seja, seriam fenômenos sempre presentes no dialeto em questão, um exemplo dessa ocorrência seria a "neutralização das vogais anteriores /e/ e /i/ e das posteriores /o/ e /u/ em posição pós-tônica ou pretônica" (BORTONI-RICARDO, 2005, p. 56), como em cantu/canto. 
A terceira categoria se constitui da interferência de regras fonológicas variáveis graduais, portanto, diz respeito a ocorrências que dependem de determinados fatores, pelo fato de serem variáveis, e que não são estigmatizadas, pelo fato de serem graduais. Exemplo deste fenômeno seria a monotongação de ditongos decrescentes, como em fera/feira.

A última categoria se distingue da terceira por se tratar de fenômenos que diferenciam os falantes e os definem, estando "presentes no repertório verbal de alguns estratos e ausentes na linguagem dos demais" (BORTONI-RICARDO, 2005, p. 56). Exemplo desse fenômeno seria a ausência de concordância verbal, como em nóis vai, por exemplo.

Bortoni-Ricardo utiliza o termo "erros" para os desvios da norma e, em estudo realizado em 2006, justifica a utilização de tal termo. Segundo a autora, a fala prevê a variação, já a escrita não, ou seja, devem-se respeitar as variadas formas de expressão linguística na modalidade oral, entretanto "na modalidade escrita, a variação não está prevista quando uma língua já venceu os estágios históricos da sua codificação. A uniformidade de que a ortografia se reveste garante sua funcionalidade.” (BORTONI-RICARDO, 2006, p. 273). Comenta, ainda, o papel do professor na tarefa de corrigir os alunos na modalidade escrita e afirma:

Considerar uma transgressão à ortografia como um erro não significa considerá-la uma deficiência do aluno que dê ensejo a críticas ou a um tratamento que o deixe humilhado. O domínio da ortografia é lento e requer muito contato com a modalidade escrita da língua. Dominar bem as regras de ortografia é um trabalho para toda a trajetória escolar e, quem sabe, para toda a vida do indivíduo. (BORTONI-RICARDO, 2006, p. 274)

Com base nesses apontamentos, pretende-se estender um olhar reflexivo em relação aos desvios da norma presentes nos textos escolares. 


\subsection{Norma e variação: o papel do professor}

A variação linguística é natural na fala; entretanto, na escrita, a língua é bastante inflexível, podendo até alterar-se, mas com o decorrer de muito tempo. Há uma norma culta, mais próxima da norma padrão, que é socialmente privilegiada, mas pouco assimilada por grande parte da população brasileira. Em vista dessa realidade, é necessário que o professor de Língua Portuguesa tenha plena consciência de sua responsabilidade em sala de aula, pois ele tanto pode reforçar como desbloquear o preconceito linguístico tão arraigado na sociedade brasileira.

É senso comum julgar pejorativamente as pessoas que falam uma norma distante da culta. O papel do professor deve, pois, centrarse nesta questão, respeitando as diversificadas normas presentes em sala, mas também propiciando o acesso à norma culta, pois, como afirma Geraldi (1984, p. 46),

é preciso romper com bloqueio de acesso ao poder, e a linguagem é um de seus caminhos. Se ela serve para bloquear e disto ninguém duvida - também serve para romper o bloqueio.

Diante desta questão, Castilho (2002, p. 33) aponta que "a melhor saída será incorporar a heterogeneidade do discipulado nas estratégias do ensino, preparando materiais didáticos que levem em conta esse fato".

É nesta perspectiva que se pretende desenvolver o presente estudo, levando o professor a refletir sobre questões linguísticas e culturais que envolvem seu trabalho escolar, com a utilização de materiais adequados à diversidade presente. Portanto, esta pesquisa objetiva sugerir propostas de ação diferenciadas para subsidiar o trabalho do profissional da linguagem.

\section{Proposta de ação}

Com base nas considerações anteriores, pode-se visualizar a sala de aula como um espaço muito propício para a abordagem da 
variação linguística, incluindo suas principais implicações, mais especificamente no que diz respeito ao preconceito linguístico, consequente do menosprezo em relação a falantes de variedades distantes da norma culta. Entre as ações a serem tomadas pelo professor de língua portuguesa, apontamos algumas que julgamos mais urgentes diante da situação em que se encontra o ensino de língua portuguesa em geral:

1. Conhecer a clientela;

2. Diagnosticar as normas presentes na sala de aula;

3. A partir do diagnóstico, preparar um trabalho específico para a turma em questão.

O primeiro item apontado, que se refere ao conhecimento do público-alvo, é fundamental para o direcionamento do trabalho do professor, uma vez que tal informação fornecerá quais as reais necessidades do alunado. Sobre tal questão, Possenti (2002) sugere, em seu estudo Umprograma minimo, algumas decisões para o trabalho docente e, entre elas, aponta a necessidade de a escola precisar conhecer sua clientela e cita: "conhecer como se fala na região em questão revelará curiosamente, eu creio, que os problemas são menos numerosos do que se imagina que são.” (POSSENTI, 2002, p. 321). O autor ainda afirma que uma análise cuidadosa revelaria que entre a fala popular e a erudita há muita coincidência, o que minimiza as possíveis inadequações; além disso, Possenti (2002) menciona que, mesmo quando um falar é muito distante da norma culta, tal falar possui regras, ou seja, possui uma gramática própria.

Este trabalho constitui uma questão, à primeira vista, simples, mas não tão óbvia quando se visualizam as reais condições de ensino em que um professor necessita ministrar entre 40 e 60 horas semanais para sua sobrevivência, o que implica um número muito grande de alunos para atender, sendo, portanto, impossível conhecer a fundo a clientela.

A segunda questão, resultante do trabalho inicial de conhecimento da clientela, é muito importante para os próximos passos do docente, pois torna possível visualizar a real situação de uma turma. Muitas vezes o professor faz uma falsa ideia do saber discente, julgando que o aluno não sabe nada sobre a língua, o que o desresponsabiliza de um trabalho específico. A partir do momento em que o professor tiver 
acesso à verdadeira situação do conhecimento linguístico do seu aluno, será capaz de propor seu trabalho e, assim, se responsabilizar pela melhoria do preparo linguístico do alunado. A respeito desta prática, conforme já citado no item 1.2. deste trabalho (Desvios da norma), Bortoni-Ricardo (2005) sugere um trabalho de análise e diagnose de erros em que propõe um levantamento minucioso dos casos distantes da norma e sugere uma interessante classificação a fim de facilitar a prática docente.

Cabe ressaltar também os já citados estudos de Miriam Lemle e de Mattoso Câmara (item 1.2 deste trabalho). Em 1957, Mattoso Câmara já propunha um diagnóstico dos desvios da norma de alunos e, seguindo tal estudo, Miriam Lemle, em 1978, efetuou estudo semelhante, mas desta vez com alunos do MOBRAL.

A terceira questão constitui, então, a proposta de ação docente, o que levará o professor a perceber a possibilidade de efetuar seu trabalho, uma vez que o ano letivo será efetivamente dispensado para isto e não para ensinar todas as questões presentes no livro didático. $\mathrm{O}$ tempo que desperdiçaria ensinando questões não urgentes pode, assim, ser dedicado a ensinar o que é realmente necessário no momento, o que certamente trará resultados muito satisfatórios.

Cabe ressaltar que um trabalho desta natureza implica total comprometimento do docente com seu trabalho, com sua tarefa de ensinar. Esse olhar torna o docente capaz de realmente realizar transformações a partir de sua prática, pois possibilita levar o aluno a se tornar um falante competente em sua língua materna, sendo capaz de adequar sua linguagem às diferentes situações de uso. Isto vem, pois, a refutar a falsa ideia de o estudo da variação resultar em um exagerado ensino permissivo, em que "tudo vale" e "tudo pode". O ensino sob um olhar sociolinguístico leva o professor a ser até mais radical em relação à norma do que em outras perspectivas, pois, no caso de ensino de gêneros em que a norma é adequada, como no caso de artigos científicos, por exemplo, o professor deverá exigir a norma padrão, sem abrir outras possibilidades, visto ser tal norma a forma adequada. 


\section{Considerações finais}

O presente estudo buscou propor algumas possibilidades de atuação do profissional da linguagem sob uma perspectiva diferenciada, visualizando a língua portuguesa em suas variadas matizes. A língua do Brasil é variada, logo, o ensino desta língua não deve se centrar apenas na norma padrão, embora este seja sim um dos trabalhos do professor de língua portuguesa. Além disso, e não menos importante, o professor de língua portuguesa, deve abordar as diferenças linguísticas presentes no país, esclarecendo questões relevantes a respeito dos valores atribuídos pela sociedade, buscando levar os alunos a rejeitarem o propagado preconceito linguístico, tão saliente em nossa nação. Finalmente, salienta-se que o verdadeiro papel do docente que se ocupa da língua no Brasil é capacitar os alunos a serem proficientes em sua própria língua, ou seja, torná-los aptos a adequarem sua forma de expressão, utilizando os níveis linguísticos adequados às situações solicitadas, o que implica o acesso à norma e o respeito às variedades.

\section{Referências}

BORTONI-RICARDO, Stella Maris. Educação em língua materna: a sociolingüística na sala de aula. São Paulo: Parábola, 2004.

Nós cheguemu na escola e agora?: sociolingüística e educação. São Paulo: Parábola, 2005.

. O estatuto do erro na língua oral e escrita. In: GORSKI, Edair Maria; COELHO, Izete Lehmkuhl (Orgs.). Sociolingüística e ensino: contribuições para a formação do professor de língua. Florianópolis: EdUFSC, 2006.

CAGLIARI, Luiz Carlos. Alfabetização e lingüística. 5. ed. São Paulo: Scipione, 1992.

CASTILHO, Ataliba Teixeira de. Variação dialetal e ensino institucionalizado da língua portuguesa. In: BAGNO, Marcos. Lingüistica da norma. São Paulo: Loyola, 2002. 
COSERIU, Eugenio. Lições de lingüística geral. Rio de Janeiro: Ao Livro Técnico, 1980.

GERALDI, João Wanderley. Concepções de linguagem e ensino de português. In: . O texto em sala de aula. São Paulo: Ática, 1984. p. 41-48.

LEMLE, Miriam. Guia teórico do alfabetizador. São Paulo: Ática, 1987.

LABOV, William. The social history of sound change on the island of Martha's Vineyard, Massachusetts. Master's essay. Columbia University, 1962.

MATTOSO CÂMARA JR, Joaquim. Erros escolares como sintomas de tendências lingüísticas no português do Rio de Janeiro. In: Dispersos. Rio de Janeiro: Fundação Getúlio Vargas, 1972. p. 35-46.

POSSENTI, Sírio. Um programa mínimo. In: BAGNO, Marcos. Lingüistica da norma. São Paulo: Loyola, 2002. 